\title{
Sentencia No. C-1008/2010 de la Corte Constitucional de Colombia y su fundamentación en la Lex Mercatoria*
}

\section{Judgment No. C-1008/2010 of the Constitutional Court of Colombia and its Foundation in the Lex Mercatoria}

\author{
Sorily Carolina Figuera Vargas ${ }^{(*)}$ \\ Academia Mexicana de Derecho Internacional Privado y Comparado \\ María Alejandra Anaya Torres ${ }^{(* * *)}$ \\ Universidad del Norte - Barranquilla, Colombia
}

\begin{abstract}
Resumen: La Corte Constitucional Colombiana, en su potestad de máxima intérprete del Texto Fundamental de este país, a través de la Sentencia C-1008 de 2010 declaró exequible el artículo 1616 del Código Civil, que regula la responsabilidad del deudor en la generación de perjuicios en materia contractual. Dentro de los fundamentos utilizados por la Corte para tomar su decisión, se encuentra el artículo 74 de la Convención de Viena sobre Compraventa Internacional de Mercaderías y el artículo 7.4.4 de los Principios UNIDROIT sobre los Contratos Comerciales Internacionales, lo cual en definitiva, representa una sustentación en la lex mercatoria. En el presente artículo las autoras analizan el mencionado fallo y disertan sobre su fundamentación en los denominados usos, costumbres y prácticas relativos al comercio internacional que deben interpretarse de forma uniforme.
\end{abstract}

Palabras claves: Corte Constitucional de Colombia - Principios UNIDROIT - Lex mercatoria - Derecho Comercial Internacional - Ley blanda.

\begin{abstract}
The Constitutional Court of Colombia, in its role as supreme interpreter of the Constitution of that country, declared article 1616 of the Civil Code as constitutional in Judgment C-1008 of 2010. Said article establishes the debtor's liability for damages in contractual matter. The Court upholds its ruling using, among other arguments, article 74 of the Vienna Convention for the International Sale of Goods and article 7.4.4 of the UNIDROIT Principles of International Commercial Contracts, which means that the ruling was widely based on the lex mercatoria. In this article, the authors analyze the Court's judgment and discuss about the uniform interpretation that the customs and practices of international commerce must be subjected to.
\end{abstract}

Key words: Constitutional Court of Colombia - UNIDROIT Principles - Lex mercatoria - International Commercial Law - Soft law.

$\left(^{*}\right) \quad$ Nota del Editor: este artículo fue recibido el 25 de octubre del 2018 y su publicación fue aprobada el 20 de noviembre de 2018.

$\left({ }^{* *}\right)$ Doctora en Derecho por la Universidad de Salamanca, Magíster en Derecho Internacional y Relaciones Internacionales por la Universidad Complutense de Madrid. Magister Scientiarum en Derecho Internacional Privado y Comparado por la Universidad Central de Venezuela. Abogada por la Universidad Bicentenaria de Aragua - Venezuela. Licenciada en Derecho en España. Miembro del llustre Colegio de Abogados de Madrid. Miembro de la Academia Mexicana de Derecho Internacional Privado y Comparado. Correo electrónico: sorilyf@ yahoo.com.

${ }^{* * *}$ Abogada e Internacionalista egresada de la Universidad del Norte, Barranquilla - Colombia. Investigadora del Programa Jóvenes Investigadores de Colciencias - Colombia, julio 2017 - julio 2018. Correo electrónico: maleanaya@hotmail.com. 


\section{Introducción}

La lex mercatoria se define como el conjunto de reglas propias del comercio internacional que nacen sin la intervención de los Estados, en el seno de organismos privados del ámbito nacional o internacional; al igual que, de órganos intergubernamentales. Se configurará mediante reglas que las partes en aplicación de la autonomía de la voluntad hacen suyas, para el manejo de sus relaciones jurídicas. Asimismo, se consideran reglas aceptadas por organizaciones de comerciantes o de prestadores de servicios, cuyo uso generalizado le otorga un carácter vinculante entre los miembros. Frente a tal caracterización, cabe preguntarse entones, si esta lex mercatoria tiene un sustento sólido y consolidado, que le permita, a su vez, fundamentar una sentencia de la Corte Constitucional Colombiana que tiene como objetivo declarar exequible o no, un artículo del Código Civil. Este estudio pretende dar respuesta a dicho cuestionamiento, mediante el análisis de la Sentencia C-1008 del 9 de diciembre de 2010 proferido por esta Corporación.

El objetivo del trabajo que se presentará en las próximas líneas, será generar una reflexión en el lector en cuanto al verdadero lugar y valor que ocupa la lex mercatoria dentro de un sistema jurídico latinoamericano como lo es el colombiano. Tal aporte académico se justifica en el creciente auge y consolidación del soft law como fuente del derecho, lo cual hace relevante su estudio.

\section{La Sentencia C-1008 de 2010 de la Corte Constitucional de Colombia: Contexto}

La Corte Constitucional colombiana mediante Sentencia C-1008 del 9 de diciembre de 2010, siendo Magistrado Ponente el Dr. Luis Ernesto Vargas Silva, se pronunció sobre la constitucionalidad del artículo 1616 del Código Civil. Este precepto regula la responsabilidad del deudor que se deriva del incumplimiento o cumplimiento tardío o imperfecto de las obligaciones contraídas bajo el marco de un contrato celebrado. El análisis se realizó a solicitud de tres ciudadanos colombianos para quienes el inciso primero del mencionado precepto transgrediría fehacientemente el articulado de la Constitución Política (en adelante, “CP"). La Corte Constitucional, luego de un análisis acucioso y fundamentándose, entre otros aspectos, en los Principios UNIDROIT, termina por declarar la exequibilidad ${ }^{(1)}$ de dicha norma.

En efecto, el primer inciso del artículo 1616 del Código Civil colombiano consagra que
"Artículo 1616.- Responsabilidad del deudor en la causación de perjuicios: Si no se puede imputar dolo al deudor, solo es responsable de los perjuicios que se previeron o pudieron preverse al tiempo del contrato; pero si hay dolo, es responsable de todos los perjuicios que fueron consecuencia inmediata o directa de no haberse cumplido la obligación o de haberse demorado su cumplimiento (...)".

Para los demandantes el enunciado normativo referido establece una distinción injusta atinente a la responsabilidad que asume el deudor incumplido cuando éste actúe con culpa en relación con aquél en cuyo accionar haya mediado dolo. De hecho, según los demandantes, esta distinción atentaría contra el Preámbulo de la Carta Política así como contra los artículos 1, 2, 13, 58, 228 y 250 del mismo texto fundamental, pues acarrea efectos adversos notorios para el acreedor a cuyo deudor se le haya imputado un comportamiento culposo en la medida en que restringe el monto de los perjuicios que habría lugar a su favor.

En este sentido, diversas razones son expuestas por los peticionarios para explicar la presunta inconstitucionalidad del artículo objeto de estudio. Como primera medida, los demandantes consideran que la limitación de la responsabilidad contractual del deudor culposo al resarcimiento exclusivo de los perjuicios previsibles, transgrediría el derecho de su acreedor a recibir una reparación integral (Preámbulo de la CP). Además, manifiestan que esta situación vulneraría igualmente el derecho a la dignidad humana (artículo 1 de la CP) debido a que la indemnización que recibiría el acreedor sería, a todas luces, desproporcionada e inequitativa. Igualmente estiman que se violaría su derecho a la igualdad (artículo 13 de la CP), pues obtendría un trato diferencial injustificable en relación con aquellos acreedores que sufrirían perjuicios con ocasión de una conducta dolosa por parte del deudor.

Del mismo modo, los demandantes alegan que el acceso a la administración de

(1) De acuerdo con Hernández Galindo, la expresión “inconstitucionalidad” tiene dos grandes acepciones. Como primera medida se entiende que la inconstitucionalidad implica una contradicción entre normas del ordenamiento jurídico y la Constitución política; y en segundo término, designa la situación jurídica que se genera a partir de la expulsión de la norma del sistema. Este segundo sentido de la expresión equivale a la denominación "inexequibilidad" que se realiza en Colombia. La inexequibilidad entonces implica la inejecutabilidad o cese forzado de la vigencia de una norma cuando el órgano competente decide retirarla del orden jurídico por ser ésta contraria a la norma fundamental $(2013,73)$. En este sentido, el concepto exequibilidad del artículo 1616 del Código Civil colombiano implica entonces la continuación de su vigencia y ejecución efectiva por su adecuación a las normas fundamentales del sistema jurídico colombiano. Así, teniendo en cuenta que el concepto de exequibilidad se encuentra dentro del género "constitucionalidad", ambos se utilizaran indistintamente en esta exposición. 
justicia también se vería afectado, pues este derecho estaría garantizado solo formalmente y no de manera efectiva o material (artículo 2 de la CP). En efecto, para ellos, la distinción en la reparación de perjuicios teniendo como criterio diferenciador el elemento subjetivo con que haya actuado el deudor, no permitiría el cumplimiento de los fines del Estado. Esto por cuanto, no habrían garantías judiciales fidedignas que le permitan al acreedor resarcir sus derechos de forma integral. De ahí que el derecho a la propiedad privada (artículo 58 de la $\mathrm{CP}$ ), se restringiría igualmente. Como argumento adicional, los demandantes consideraron que, además de las razones sustanciales mencionadas, debería tenerse en cuenta que el artículo 1616 del Código Civil fue derogado por el artículo 16 de la Ley 446 de 1998 y por lo tanto, tal precepto no se encontraría actualmente vigente.

Sobre las razones alegadas por la parte demandante, la Corte Constitucional expresó en su sentencia, diversas consideraciones relacionadas con la responsabilidad civil contractual en Colombia, las cuales le permitieron finalmente declarar exequible el artículo 1616 del Código Civil. De esta forma, este Alto Tribunal se refirió inicialmente, a la tesis dualista sobre la responsabilidad civil que adopta el ordenamiento jurídico colombiano, considerando que la distinción entre la responsabilidad contractual y la extracontractual se tornaba pertinente en este caso. La razón de ello se hizo manifiesta en la necesidad de aclarar que los efectos resarcitorios de ambos tipos de responsabilidades no pueden equipararse toda vez que ellas son sustancialmente distintas.

Así, la Corte afirmó que en Colombia existen dos tipos diferentes de responsabilidad civil. Por un lado, se encuentra la responsabilidad contractual que se deriva del incumplimiento o cumplimiento tardío o imperfecto de una obligación contraída de manera voluntaria; y por otro, la responsabilidad extracontractual que se origina propiamente en un hecho jurídico. La clasificación en una u otra, no se realiza con motivos meramente pedagógicos, sino que de forma efectiva, ambas responsabilidades difieren en sus aspectos fundamentales y por lo tanto, sus efectos serán también distintos.

Entre estos efectos se encuentra, por supuesto, la correspondiente reparación de perjuicios generados al acreedor, pues la indemnización respectiva será avaluada de acuerdo al tipo de responsabilidad de la que se trate. Así, a la luz de la responsabilidad contractual, los perjuicios pueden estar limitados por la autonomía de la voluntad ${ }^{(2)}$ y por la naturaleza y alcance de la obligación incumplida. Estos aspectos no son posibles para el caso de la responsabilidad extracontractual debido a que ésta tiene su origen en la ley y no en contrato alguno. Adicionalmente, el Código Civil colombiano regula autónomamente cada tipo de responsabilidad, otorgándole a cada una su respectivo tratamiento particular(3).

Sin embargo, el tratamiento diferencial no se limita a esta dicotomía inicial. En efecto, para la Corte, la responsabilidad contractual atribuible al deudor incumplido se determina igualmente a partir del elemento subjetivo que haya mediado en su conducta, siendo entonces posible identificar culpa grave (también denominada como negligencia grave o culpa lata), culpa leve (descuido leve o descuido ligero), culpa levísima (descuido levísimo) y dolo. Los diferentes tipos de elementos subjetivos determinarán entonces el grado de indemnización de perjuicios derivado de la responsabilidad civil contractual. Vale mencionar que, el legislador colombiano equipara los efectos del dolo a la culpa grave(4) en tratándose de la reparación del daño generado al acreedor.

De todas formas, para la Corte Constitucional la culpa, en términos generales, y el dolo son elementos subjetivos notoriamente distintos, pues la primera:

“(...) se presume en el incumplimiento contractual (...) las partes pueden alterar las regulaciones legales respecto de ella y su intensidad se gradúa para asignar diferentes efectos a sus diversos grados (artículo 1604) y por último no agrava la posición del deudor sino ante los que previó o pudo preverse al tiempo del contrato (artículo 1616 C.C) (...) el dolo generalmente no se presume (artículo 1516 C.C) ni su tratamiento legal puede ser modificado por la voluntad individual (...) acarrea en todos los casos sanciones civiles de igual intensidad y agrava la posición del deudor aún en frente de eventos imprevisibles (artículo 1616 C.C)" (Corte Suprema de Justicia, T. LXVI, 356, citada en Corte Constitucional 2010).

Las diferencias sustanciales entre la culpa generalmente considerada y el dolo, constituyen la justificación que permite explicar la diferencia de criterios que han de tenerse en cuenta al momento de determinar los perjuicios

(2) El último inciso del artículo 1616 del Código Civil establece que "las estipulaciones de los contratantes podrán modificar estas reglas", por lo tanto las partes podrán extender o reducir su responsabilidad en ejercicio de su derecho a la autonomía de la voluntad.

(3) Así, la responsabilidad contractual se encuentra plasmada fundamentalmente en los artículos 63 y 1604 del Código Civil, mientras que la responsabilidad extracontractual es regulada en los artículos 2341 y 2356 del mismo Estatuto.

(4) De acuerdo con el artículo 63 del Código Civil, la culpa grave consiste en "no manejar los negocios ajenos con aquel cuidado que aún las personas negligentes o de poca prudencia suelen emplear en los negocios propios". Así, tanto para el deudor que actúe con dolo como aquél que lo haga con culpa grave, deberá responder por los perjuicios previsibles e imprevisibles causados. 
por los que deba responder el deudor incumplido. En el caso colombiano, el parámetro utilizado para la determinación del monto de la indemnización de perjuicios cuando en la conducta del deudor haya mediado culpa es la previsibilidad del daño. La Corte Constitucional colombiana consideró además que este particular parámetro se encuentra acorde con la regulación internacional proferida sobre la materia, considerando la Convención de Viena sobre Compraventa Internacional de Mercaderías (artículo 74) y los Principios UNIDROIT sobre los Contratos Comerciales Internacionales (artículo 7.4.4).

La previsibilidad del daño entonces se basa en la idea de que los perjuicios pudieron haber sido previstos por parte del deudor si éste hubiera actuado con la diligencia debida. Sin embargo, cuando el deudor incurre en dolo, la responsabilidad se extiende a los perjuicios imprevisibles que ocasionó el incumplimiento. Esta distinción, de acuerdo con la Corte, pone de presente la intención maliciosa o la conciencia de quebrantar una obligación que se deriva de una conducta dolosa o gravemente culposa. De ahí que la actitud asumida por el deudor tenga relevancia en la cuantía de la indemnización por la cual deba responder.

La Corte expuso además, que la decisión tomada por el legislador colombiano en cuanto a la regulación de la responsabilidad civil contractual así como sus efectos, descansa en la amplia potestad de libre configuración legislativa que le otorga la Carta Política en su artículo 58. Su única limitación son los principios consagrados en la Constitución Política y el orden público, resaltando particularmente el principio de la autonomía de la voluntad de las partes que rigen las relaciones contractuales y su fundamento en el derecho al libre desarrollo de la personalidad consagrado en el artículo 16 de la CP.

De forma adicional vale mencionar que, el artículo 16 de la Ley 446 de 1998 alegado por los demandantes, no derogó expresa ni tácitamente el artículo 1616 del Código Civil. El precepto en mención se refiere a la reparación integral que deben guiar todos los procesos de reparación de perjuicios, sin embargo, la norma no deroga el artículo referido del Código Civil toda vez que, para la Corte, el artículo 1616 de este Estatuto establece limitaciones a este principio basadas en la equidad y en la tradición basada en la culpa de la responsabilidad contractual en Colombia.

Estas razones entonces descartan la inconstitucionalidad alegada por los demandantes, teniendo en cuenta que el legislador, en ejercicio de su derecho a la libre configuración normativa, ha regulado los efectos del resarcimiento de perjuicios teniendo como fundamento el principio de equidad. Así, la limitación al principio de reparación integral que se observa en la indemnización de perjuicios al acreedor cuando su deudor actúa con culpa, no constituye una decisión reprochable ni irrazonable. Esto, debido a que se justifica otorgarle un trato más favorable al deudor que no se ha comportado de mala fe respecto a aquél que actúa mal de forma deliberada. De ahí que el orden justo, como fin del Estado, no se ponga en tela de juicio en virtud del artículo 1616 del Código Civil.
Tampoco se violaría entonces el derecho a la igualdad, pues la culpa y el dolo son elementos subjetivos distintos y/o disímiles que involucran por ello, efectos sumamente diferentes. Por la misma razón mencionada no se afecta el principio de la dignidad humana, pues la distinción consagrada en el mencionado precepto reafirma la autonomía y capacidad del individuo para proyectarse en el contrato respectivo. Adicionalmente, el principio de acceso a la administración de justicia quedaría indemne, teniendo en cuenta que en cualquier caso, cuando medie dolo o culpa por parte del deudor, el acreedor tiene todo su derecho de iniciar una acción ante los estrados judiciales. La limitación a los perjuicios que conlleva la actuación de un deudor culposo en relación al doloso, se encuentra justificada en principios básicos del ordenamiento jurídico y por lo tanto la distinción no implica un quebranto a la tutela resarcitoria que recae en cabeza del acreedor.

Así, los distintos efectos en materia de reparación de perjuicios según el criterio de la Corte Constitucional, se encuentran justificados en el principio de equidad, como principio general del derecho, así como en la tesis dualista de la responsabilidad civil que rige el ordenamiento jurídico colombiano. Paralelamente, cobra relevancia los efectos disimiles que apareja la conducta dolosa y culposa en materia contractual. Sobre este último aspecto, la Corte es enfática en establecer la libertad de configuración legislativa que pregona el legislador en Colombia, en cuanto a los efectos que acarrean una u otra conducta, poniendo de manifiesto igualmente, que la regulación nacional se equipara con la tendencia en la materia que a nivel internacional se ha consolidado.

\section{Análisis del artículo 1616 del Código Civil colombiano}

El artículo 1616 del Código Civil colombiano se inscribe dentro de la categoría conceptual de la responsabilidad contractual. De acuerdo con la jurisprudencia de la Corte Suprema de Justicia, la misma se configura cuando median sus elementos fundamentales, siendo éstos, la preexistencia de un negocio jurídico constituido de forma válida -el cual equivale a la fuente de obligaciones entre las partes-, la inejecución o ejecución tardía de las obligaciones contraídas por parte del deudor, el menoscabo o daño 
sufrido sobre el patrimonio del acreedor y el subsecuente nexo de causalidad entre estos dos últimos elementos (Corte Suprema de Justicia, Sala de Casación Civil 1996).

Este tipo de responsabilidad difiere ampliamente de aquella denominada como aquiliana o extracontractual, en virtud del origen de las obligaciones contraídas, pues esta última opera entre quienes el azar ha vinculado sin que entre ellos haya mediado voluntad de hacerlo. De ahí que la regulación estipulada en el Código Civil colombiano para cada uno de estos tipos de responsabilidad sea sustancialmente distinta y autónoma, reglamentándolas en diferentes capítulos del Libro IV del mismo Estatuto. De todas maneras, vale aclarar, que en cualquiera de los casos será procedente la correspondiente reparación de perjuicios cuando medie daño imputable al deudor o, en su defecto, al que ha inferido daño a otro por haber cometido delito o culpa (artículo 2341 del Código Civil).

En lo que concierne específicamente a la responsabilidad contractual debe tenerse en cuenta que la conducta del deudor incidirá en gran medida en el tipo y cuantía de los perjuicios que deberá resarcir a favor del acreedor como consecuencia del incumplimiento de sus obligaciones contractuales. Esto es así debido a que la naturaleza de la conducta del deudor viene dada por elementos subjetivos que involucran efectos distintos. De hecho, el artículo 63 del Código Civil define los disímiles tipos de culpas existentes en el ordenamiento jurídico colombiano así como el dolo, los cuales difieren sustancialmente entre sí.

Por un lado, el dolo(5) como elemento subjetivo en materia contractual, implica la "conciencia de quebrantar una obligación de vulnerar un interés jurídico ajeno" (Tafur González, Código Civil Anotado, artículo 63); por otro, la culpa implica "la falta de diligencia o de cuidado, de imprevisión, la negligencia, la imprudencia" (Tafur González 2010). La diferencia que realiza el artículo 1616 del Código Civil colombiano en cuanto a la correspondiente reparación del daño, tiene en cuenta el alcance de cada una de estas posibles conductas. De igual manera, la diferenciación consagrada en el precepto referido tiene como fundamento los principios de buena fe y equidad que irradian la totalidad del sistema jurídico.

En este sentido, no debe perderse de vista la interpretación sistemática como método hermenéutico de la ley. En efecto, la interpretación sistemática considera que el sentido de las normas debe entenderse teniendo en cuenta el ordenamiento jurídico en su conjunto. Esto por cuanto, las estipulaciones normativas no son proferidas de forma aislada y no pueden, por lo tanto, ser entendidas fuera del contexto al que pertenecen (Piccato 2006). Adicionalmente, la Corte Constitucional ha aludido en reiteradas ocasiones sobre el tema, estableciendo que:
"De nada sirve el ejercicio de interpretación que se reduce a los límites de una sola disposición (...) cuando la adecuada compresión de dicho precepto depende de la integración de artículos contenidos en otras regulaciones. El ordenamiento jurídico presenta con frecuencia normas incompletas, cuyo contenido y finalidad deben articularse junto a otras reglas; sólo de este modo es posible superar supuestas incongruencias al interior de un orden normativo" (Corte Constitucional 2000b).

De ahí que la interpretación del artículo 1616 se realice conforme a criterios y principios generales del derecho que insten a la consecución de un orden social justo (artículo 3 de la CP). Del mismo modo debe considerarse el artículo 1603 del Código Civil, pues el mismo consagra el principio de buena fe en materia contractual y obliga a las partes involucradas en un determinado negocio jurídico, al cumplimiento de las obligaciones en él contraídas. En este sentido, Velásquez Gómez considera que debido a que el que actúa con dolo no es diligente y asume una posición deliberada de incumplir, se le atribuya la máxima responsabilidad en relación al resarcimiento de perjuicios (2010). Por esta razón, el hecho de que el deudor doloso sea también responsable de los perjuicios imprevisibles, constituye un criterio completamente plausible en el orden jurídico colombiano, toda vez que se evidencia en su conducta, una vulneración intencionada al principio rector de buena fe contractual.

De igual manera, el concepto de culpa entendida como negligencia o impericia en el cumplimiento del contrato, alude al hecho de que el deudor, pudiendo prever el daño antijurídico que podría causar con su conducta, no lo hace y falla a sus obligaciones. Sin embargo, este incumplimiento no se predica sino de la falta del debido cuidado en su actuación y por tanto difiere sustancialmente de la actitud que asume el deudor doloso. Al respecto, la Corte Suprema de Justicia colombiana ha dicho que la falta contractual consiste en "la inejecución previsible y evitable,

(5) Si bien el dolo de acuerdo con el artículo 63 del Código Civil se define como "la intención positiva de inferir injuria a la persona o propiedad de otro", la doctrina ha entendido que dicha definición corresponde al dolo que constituye vicio del consentimiento y no al dolo que provoca el incumplimiento de obligaciones contractuales. Así, en materia contractual, no es necesario que el deudor doloso actúe con la "intención expresa de perjudicar a su acreedor" (Velásquez 2010,686), sino que basta con la simple voluntad de incumplir para que el mismo se configure. Esto por cuanto sería muy difícil demostrar que con el incumplimiento el deudor pretendía a todas luces perjudicar a su acreedor y por lo tanto, sería poco probable que los perjuicios imprevisibles se hicieran efectivos en algún caso (Tamayo Jaramillo 1999, 199). 
por una parte contratante o por sus causahabientes frente a la otra parte contratante o sus causahabientes, de una o varias obligaciones nacidas de un contrato que a ambos extremos vincula" (Corte Suprema de Justicia, Sala de Casación Civil 1999).

Ahora bien, es menester aclarar que en el caso del deudor incumplido por culpa, importa poco si éste previó o no los perjuicios que podrían causarse por su actuación, sino que simplemente se tendrá en cuenta si los mismos eran normalmente previsibles. De ahí que se "indemnice el perjuicio previsible, así no haya sido previsto por el deudor" (Velásquez Gómez 2010, 872).

Debe tenerse en cuenta igualmente que sobre este tipo de responsabilidad sólo responderán aquellos deudores que hayan actuado con culpa leve o levísima toda vez que la culpa grave, por consideración del legislador, se asemeja al dolo en cuanto a responsabilidad por daños se refiere. La razón de ser de esta equiparación se basa en la cautela que ha tenido el órgano legislativo de evitar que el deudor doloso, al actuar de mala fe, se escude en una supuesta negligencia grave para eximirse de responsabilidad. No por nada se afirma con vehemencia que "entre el muy torpe y el mal intencionado existe una línea diferenciadora muy sutil” (Velásquez Gómez 2010, 687).

\section{La responsabilidad del deudor en materia de indemnización de perjuicios en el ámbito contractual privado fundamentada en la lex mercatoria}

Como se señaló anteriormente, la previsibilidad del daño es el parámetro utilizado por el artículo 1616 del Código Civil colombiano para determinar la indemnización de perjuicios cuando en la conducta del deudor haya mediado culpa. En tal sentido la Corte Constitucional, en su Sentencia C-1008 de 2010, determinó que dicho parámetro se ajusta a las estipulaciones internacionales previstas en el artículo 74 de la Convención de Viena sobre Compraventa Internacional de Mercaderías y el artículo 7.4.4 en los Principios sobre Contratos de la UNIDROIT. De allí que, se puede aseverar que el mencionado fallo tuvo fundamento en la lex mercatoria.

La expresión nueva lex mercatoria comenzó a utilizarse por Berthold Goldman, Clive Schmitthoff y Pierre Lalive a comienzos de la década de 1950. Actualmente, el adjetivo nueva se emplea para hacer la distinción de la lex mercatoria medieval que tuvo vigencia desde inicios del siglo XII y perduró por más de cuatro siglos (Cadena Afanador 2006). Entre las semejanzas de la vieja y la nueva lex mercatoria están: a) su conformación por usos que constituyen un Derecho espontáneo, uniforme, y en cierta manera universal; b) que son usos propios de los comerciantes; y c) que son usos que tratan de superar las dificultades del conflicto de leyes cuando se trata de determinar el Derecho nacional que regirá determinada relación jurídica. Sus diferencias de contenido se enfocan en que con la nueva lex mercatoria se está ante un Derecho espontáneo, nacido de la práctica comercial internacional, con unas fuentes propias y unos medios de solución de litigios de intereses específicos al margen del poder judicial de los Estados y de los Tribunales internacionales (Fernández Rozas 2002).

Fernández Rozas (2002) justifica la existencia de la nueva lex mercatoria de la siguiente manera:

"La tendencia hacia la internacionalidad de las transacciones mercantiles ha originado un aumento espectacular de los protagonistas en presencia, la existencia, ciertamente discutida, de un ordenamiento jurídico y la consolidación de peculiares procedimientos de controversias al margen del Estado. Pero también ha propiciado un acercamiento entre los ordenamientos interno e internacional y, en ocasiones, la unificación de las legislaciones estatales, cuyo ámbito de vigencia no se corresponde empero con las exigencias de uniformidad que el comercio internacional plantea. Por eso en la actualidad se habla de una nueva lex mercatoria".

En definitiva la nueva lex mercatoria se ha conceptualizado como el conjunto de reglas propias del comercio internacional que se constituyen sin la intervención de los Estados, puede ser a través de organismos privados del ámbito nacional o internacional; así como, por órganos intergubernamentales. Está conformada por reglas que las partes se apropian, en aplicación de la autonomía de la voluntad, para el manejo de sus relaciones jurídicas o, igualmente, son reglas aceptadas por organizaciones de comerciantes o de prestadores de servicios, cuyo uso generalizado le otorga un carácter vinculante entre los afiliados (Bolaños Linares 2004).

En relación con las fuentes de la lex mercatoria, destacados autores comparten la idea que la misma emerge desde tres ámbitos. Inicialmente, se dice que proviene de los principios generales del derecho relativos a las relaciones comerciales internacionales; luego, de los usos y prácticas uniformes observados en el comercio internacional, definidos como todas aquellas reglas formuladas por ciertas asociaciones públicas o privadas, donde surgen usos generalmente seguidos en dicho contexto y; por último, nace de las reglas surgidas de la práctica arbitral internacional. En relación a esta última, existe unanimidad al 
afirmar que la jurisprudencia arbitral es una fuente relevante de la lex mercatoria; incluso, se ha dicho que mediante el arbitraje los comerciantes van creando su propio sistema regulatorio (Madrid Martínez 2013).

Ahora bien, la Sentencia C-1008 de 2010 de la Corte Constitucional estableció que la previsibilidad del daño consagrado en el artículo 1616 del Código Civil colombiano para determinar la indemnización de perjuicios cuando en la conducta del deudor haya mediado culpa, era acorde en primer lugar, con el artículo 74 de la Convención de Viena sobre Compraventa Internacional de Mercaderías. Este instrumento internacional fue elaborado por la Comisión de Naciones Unidas para el Derecho Mercantil Internacional (CNUDMI), el 11 de abril de 1980 y entró en vigor el 1 de enero de 1988:

"Con el objeto de evitar los problemas que para el desarrollo del comercio internacional supone la existencia de una pluralidad de ordenamientos jurídicos nacionales, dotados de soluciones diferenciadas y no siempre apropiadas para regular los contratos de compraventa internacional de mercadería (...)" (Esplugues Mota, Palao Moreno y Fernández Masiá 2003, 169)

Si bien es cierto que parte de la doctrina considera la Convención de Viena sobre Compraventa Internacional de Mercaderías como fuente de la lex mercatoria, en realidad cada vez es más sólida la tendencia que se inclina por catalogar este instrumento internacional como uno de los representantes más importantes del derecho material uniforme ${ }^{(6)}$ (Campuzano 2000). Por consiguiente, incluir dentro de la lex mercatoria a este tipo de tratados, que se fundamentan en el acuerdo entre Estados para generar normas comunes, representaría una excepción al carácter anacional, privado y espontáneo que se le atribuye a la primera (Ochoa 2005).

No obstante lo antes señalado, la lex mercatoria y el derecho material uniforme tienen influencias mutuas y mantienen una relación de complementariedad. Así por ejemplo, se ha señalado cómo el derecho uniforme puede adoptar los principios que surgen de la sociedad de comerciantes, coadyuvando a establecer su contenido y generar una mayor aplicación. Por otra parte, se ha considerado que la condición incompleta y fragmentada de la lex mercatoria, acarrea la necesidad de un derecho de fondo que fije sus principios esenciales, siendo el idóneo el derecho uniforme, que se ha creado para dar una respuesta a las exigencias del comercio internacional (Campuzano 2000).

La Convención de Viena sobre Compraventa Internacional de Mercaderías fue ratificada por Colombia mediante la Ley 518 de agosto 4 de 1999. Texto legal declarado exequible por la Corte Constitucional a través de la Sentencia C-529 de 2000.
Ya ciñéndonos al tema que nos ocupa en este análisis, cabe establecer que el artículo 74 de la Convención de Viena, que sirvió de fundamento para los criterios acogidos por la Sentencia C-1008 de 2010 de la Corte Constitucional, establece:

"Artículo 74.- La indemnización de daños y perjuicios por el incumplimiento del contrato en que haya incurrido una de las partes comprenderá el valor de la pérdida sufrida y el de la ganancia dejada de obtener por la otra parte como consecuencia del incumplimiento. Esa indemnización no podrá exceder de la pérdida que la parte que haya incurrido en incumplimiento hubiera previsto o debiera haber previsto en el momento de la celebración del contrato, tomando en consideración los hechos de que tuvo o debió haber tenido conocimiento en ese momento, como consecuencia posible del incumplimiento del contrato".

En realidad la Sentencia C-1008 de 2010 de la Corte Constitucional se limitó a citar el artículo 74 antes expuesto, como uno de los sustentos para declarar la exequible el artículo 1.616 del Código Civil de Colombia. Sin embargo, resulta interesante profundizar en el estudio de cómo ha sido analizada esta disposición en el ámbito internacional.

Las interpretaciones del artículo 74 restringe la indemnización de daños y perjuicios a la pérdida que la parte que haya incurrido en incumplimiento, hubiera previsto o debiera haber previsto en el momento de la celebración del contrato, como consecuencia posible de su incumplimiento. En tal sentido, se estima que el requisito de previsibilidad que consagra el artículo 74 de la Convención de Viena, alude a las posibles consecuencias del incumplimiento y no a la posibilidad de que el contrato se incumpla o el tipo de incumplimiento; sugiriéndose además, que este artículo no exige que sean previsibles los detalles específicos de la pérdida (CNUDMI 2010).

Es así como, varios fallos en el ámbito internacional han afirmado que los daños y perjuicios cuya indemnización se exigía eran

(6) Para CNUDMI la unificación del derecho consiste en la "aprobación por los Estados de normas jurídicas comunes aplicables a determinados aspectos de las operaciones comerciales internacionales. Una ley modelo o una guía legislativa ejemplifican el tipo de texto cuya finalidad es armonizar el derecho interno, mientras que una convención es un instrumento internacional aprobado por los Estados para unificar el derecho a nivel internacional. Entre los textos preparados por la CNUDMl figuran convenciones, leyes modelo, guías jurídicas, guías legislativas, reglamentos y notas prácticas". Disponible en: http://www.uncitral.org/uncitral/es/about/origin_faq.html. Recuperado el 15 de marzo de 2015. 


\section{Sentencia No. C-1008/2010 de la Corte Constitucional de Colombia y su fundamentación en la Lex Mercatoria}

previsibles, con fundamento en el artículo 74 de la Convención de Viena. Citando un par de ejemplos, se puede exponer como un laudo arbitral estableció que el vendedor que había incumplido debió prever las pérdidas del comprador porque había mantenido con él una abundante correspondencia sobre los problemas de suministro (Caso CLOUT No 166, Arbitraje - Schiedsgericht der Handelskammer Hamburg, 21 de marzo de 1996). Igualmente, se ha dictaminado que un comprador pudo prever que su incumplimiento, cuando no expidió una carta de crédito como se estipulaba en el contrato de compraventa, dejaría al vendedor con un buque fletado que no podría utilizar, por lo cual podía solicitarse el resarcimiento de los gastos en que había incurrido el vendedor para subcontratar dicho buque con sustento en el artículo 74 del Convenio de Viena (Caso CLOUT No 631, Supreme Court of Queensland, Australia, 17 de noviembre de 2000); entre muchos otros casos.

Siguiendo con el análisis de la Sentencia C-1008 de 2010 de la Corte Constitucional, se debe reiterar que el fallo también citó el artículo 7.4.4 de los Principios UNIDROIT sobre los Contratos Comerciales Internacionales, como segundo fundamento del criterio de la previsibilidad del daño consagrado en el artículo 1616 del Código Civil colombiano, para fijar la indemnización de perjuicios consecuencia de la culpa del deudor.

Dichos Principios emanaron del Instituto para la Unificación del Derecho Privado (UNIDROIT), que es una organización intergubernamental fundada en 1926, bajo el auspicio de la Liga de Naciones. Luego, el 15 de marzo de 1940 se reestableció mediante la adopción del Estatuto Orgánico de UNIDROIT(7). En la ciudad de Roma se encuentra su sede y se instituyó con el objetivo de promover la armonización y unificación del derecho privado a nivel internacional, considerando la creciente liberalización del comercio y el proceso de integración económica. Actualmente 63 Estados de los cinco continentes son miembros de la organización ${ }^{(8)}$ (Oviedo 2002; Tolosa 2017; Momberg-Uribe \& Pino-Emhart 2018).

Para la celebración de los 40 años de la fundación de UNIDROIT en Roma, se planteó la iniciativa de confeccionar un cuerpo normativo para los contratos comerciales internacionales. Fue así que el Consejo Directivo de UNIDROIT reunido en 1971 incluyó en la agenda de trabajo la preparación de un ensayo de unificación relativo a la parte general de los contratos. Para 1980 se conformó el grupo de trabajo, constituido por representantes de diversas culturas y sistemas jurídicos del mundo (Civil law, Common law y sistemas socialistas). En 1994 se culminó la labor con la publicación de los Principios para los Contratos Comerciales Internacionales. (Oviedo 2002).

Los Principios UNIDROIT sobre los Contratos Comerciales Internacionales han sido definidos como un conjunto de reglas articuladas y comentadas por los redactores, que se encuentran disponibles para los interesados como un modelo de reglamentación aplicable a sus relaciones contractuales. Una de sus características distintivas es el no ser vinculantes u obligatorios para los contratantes, a menos que estos hayan elegido su aplicación en ejercicio de la autonomía de la voluntad. Se presentan como un texto concatenado, cuyo objetivo es la armonización jurídica sustantiva de la parte general de los contratos comerciales internacionales (Pablo - Romero 2014). Hasta la fecha se han dado cuatro ediciones de estos Principios, la primera en 1994, la segunda en 2004, la tercera en 2010 y la cuarta en 2016.

Los Principios UNIDROIT son considerados soft law, expresión que hace mención a instrumentos cuya juridicidad o fuerza vinculante es ambigua o se cuestiona, aunque poseen cierta relevancia jurídica. En tal sentido son catalogados como soft law, en base al segundo párrafo del preámbulo del instrumento, que hace depender su aplicación a la autonomía de la voluntad de los contratantes.

Los Principios UNIDROIT en definitiva se consideran,

"Instrumentos cuasilegales que por sí mismos no son vinculantes jurídicamente, por carecer de rango normativo, ya que las instituciones que los crean no tienen poder legislativo. Solo son recomendaciones, declaraciones, principios, códigos de conducta, que emiten algunos organismos internacionales y que cada vez adquieren más relevancia en la práctica legal internacional por su creciente utilización". (Cándano 2018, 154).

De tal manera, los Principios UNIDROIT destacan como una expresión de la lex mercatoria, en base a lo establecido en el tercer párrafo del preámbulo: "Estos Principios pueden aplicarse cuando las partes hayan acordado que su contrato se rija por principios generales del derecho, la "lex mercatoria" o expresiones semejantes" (2016).

Estos Principios se tratan entonces de un sistema normativo blando, elaborado por una organización independiente, que no tienen fuerza vinculante, ya que precisamente, no son un precepto estatal. Sin embargo, tienen una amplia acogida voluntaria entre la comunidad empresarial, debido a su calidad técnica que permiten equilibrar la práctica mercantil con el desarrollo económico y tecnológico (Ruiz 2016, 347).

(7) Incorporado en el sistema jurídico colombiano mediante la Ley 32 del 30 de diciembre de 1992.

(8) Para verificar los Estados miembros consultar: http://www.unidroit.org/about-unidroit/membership 
El contexto antes expuesto, es el que permite afirmar que la Sentencia C-1008 de 2010 de la Corte Constitucional fundamentó su decisión en la lex mercatoria, cuando citó el artículo 7.4.4 de los Principios UNIDROIT sobre los Contratos Comerciales Internacionales, que consagra

"Artículo 7.4.4 (Previsibilidad del daño). La parte incumplidora es responsable solamente del daño previsto, o que razonablemente podría haber previsto, como consecuencia probable de su incumplimiento, al momento de celebrarse el contrato".

La fórmula adoptada por el artículo 7.4.4 de los Principios UNIDROIT corresponde a la solución adoptada por el artículo $74 \mathrm{del}$ Convenio de Viena sobre Compraventa Internacional de Mercaderías. Como ejemplo de la interpretación que se ha dado al contenido de esta norma, se citará un laudo arbitral del Centro de Arbitraje de México (CAM), del 30 de noviembre de 2006, que dictaminó que la previsibilidad de los daños tiene una definición particular bajo los Principios UNIDROIT, la cual implica que sean razonablemente observables por una persona diligente. De allí que se cuestionó si los daños que la parte actora alegaba eran razonablemente previsibles para el demandado al momento de la celebración del contrato, a lo cual el tribunal arbitral respondió afirmativamente ${ }^{(9)}$.

Así pues, luego de estudiar el contenido, interpretación, naturaleza y aplicación práctica del artículo 74 de la Convención de Viena sobre Compraventa Internacional de Mercaderías y el artículo 7.4.4 en los Principios sobre Contratos de la UNIDROIT, corresponde ahora analizar la potestad que tiene la Corte Constitucional de Colombia, para considerar exequible el artículo 1616 con fundamento en la lex mercatoria.

\section{Potestad de la Corte Constitucional Colombiana para determinar exequible un artículo del Código Civil sobre responsabilidad contractual fundamentándose en la lex mercatoria}

La competencia de los Tribunales Constitucionales en cuanto a la protección del texto fundamental que rige el conjunto del ordenamiento jurídico, tiene su razón de ser en el principio de supremacía de la Constitución que, en palabras de Kelsen, "representa la suprema validez de todo el orden jurídico" (1995, 146). El caso colombiano no es ajeno a esta teoría general del derecho, pues el artículo 4 de la Carta Política colombiana consagra que "la Constitución es norma de normas. En todo caso de incompatibilidad entre la Constitución y la ley u otra norma jurídica, se aplicarán las normas constitucionales".
En este sentido, el principio referido se encuentra previsto en las normas iusfundamentales relacionadas en la Constitución Nacional. Así, el mismo implica que la Carta Política no puede ser contrariada por normas de inferior jerarquía que integren el sistema, debido a que la validez de estas últimas se desprende necesariamente de su ajuste a las normas de más alto nivel (Hernández Galindo 2013, 37). Para garantizar la indemnidad de este precepto, las Constituciones de forma general, le atribuyen a órganos estatales ${ }^{(10)}$ la obligación de ejecutar mecanismos de control de constitucionalidad.

En Colombia la guarda de la supremacía de la Carta Fundamental y por consiguiente el ejercicio del control de constitucionalidad, en términos generales, radica en la Corte Constitucional. Sin embargo, en contraposición con el modelo concentrado o europeo de control, este ordenamiento jurídico en particular consagra otros mecanismos que recaen en cabeza de todos los servidores públicos en su conjunto, abarcando también elementos del modelo difuso o norteamericano de este tipo de control.

De tal manera, la Constitución Política de Colombia le otorga la facultad al Consejo de Estado, como máximo órgano de lo Contencioso Administrativo, el conocimiento de demandas de inconstitucionalidad sobre los decretos generales dictados por el Gobierno Nacional cuya atribución no se le haya otorgado a la Corte Constitucional (artículo 236.3 de la CP). De igual manera, recae en cabeza de las autoridades estatales el control concreto por vía de excepción, configurándose cuando se presenta una contradicción evidente entre una norma del ordenamiento jurídico y el contenido constitucional. En estos casos entonces, la autoridad no deberá aplicar la ley en el caso concreto para darle prevalencia a la Constitución Política (artículo 4 inciso 2 de la CP). No menos importante es el caso que enfrentan todos los jueces de la República cuando se trata de la Acción de Tutela(11), pues la misma constituye

(9) Laudo arbitral consultado en original en: http://www.unilex.info/case.cfm?pid=case\&id=1149\&step=FullText

(10) De acuerdo con Naranjo Mesa (2014), a lo largo de la historia no ha existido unanimidad en la materia en cuanto al órgano facultado para ejercer el control de constitucionalidad. En efecto, tal competencia puede ser atribuida a un cuerpo político como el Parlamento por ejemplo o a un órgano de carácter jurisdiccional como lo sería el caso propio de los Tribunales Constitucionales especializados o las Salas Constitucionales de un Tribunal Superior (404 y 405).

(11) La Acción de Tutela en Colombia se encuentra consagrada en el artículo 86 de la Constitución Nacional. Esta figura corresponde al recurso judicial que propende por la protección de los derechos constitucionalmente reconocidos a todos los nacionales, de ahí que se le dé prevalencia a los derechos iusfundamentales cuando normas infraconstitucionales atenten contra ellos. Este mecanismo se equipara a la Acción de Amparo existente en el caso Mexicano (Vivas Barrera 2012). 


\section{Sentencia No. C-1008/2010 de la Corte Constitucional de Colombia y su fundamentación en la Lex Mercatoria}

un mecanismo expedito para la protección de los derechos fundamentales consagrados en el texto fundamental. (Quinche 2013, 301).

Al respecto, la Corte Constitucional de Colombia en las Sentencias C-1154 de 2008 así como en la C-400 de 2013, expuso que:

“(...) el constituyente de 1991, al regular la manera como debe preservarse la supremacía e integridad de la Constitución, optó por un modelo de control constitucional que la jurisprudencia ha llamado difuso funcional. En este esquema concurren, por un lado, la Corte Constitucional y el Consejo de Estado, como órganos encargados del control abstracto de constitucionalidad y, por el otro, todos los jueces y corporaciones que deben decidir las acciones de tutela o resolver acciones y recursos previstos para garantizar los derechos constitucionales o al hacer uso de la excepción de inconstitucionalidad en los casos concretos sometidos a su consideración (...)".

Ahora bien, de forma particular, la competencia sobre el control de constitucionalidad que recae en la Corte Constitucional, se encuentra regulada en el artículo 241 de la norma de normas. Para tal efecto, este Alto Tribunal conocerá sobre las demandas de inconstitucionalidad presentadas por los ciudadanos contra los actos reformatorios de la Constitución (241.1), los decretos con fuerza de ley (241.5), decretos legislativos que expida el Gobierno Nacional (241.7), proyectos de ley objetados por el Gobierno como inconstitucionales (241.8) así como contra las leyes en términos generales alegadas por cualquier persona (241.4). Adicionalmente tiene competencia para pronunciarse sobre la exequibilidad de los tratados internacionales y las leyes aprobatorias de los mismos (241.10), e igualmente la constitucionalidad de una convocatoria a un referendo o Asamblea Nacional Constituyente para reformar la Constitución (241.2), referendos sobre leyes, consultas populares, plebiscitos (241.3), entre otros aspectos.

La competencia de la Corte Constitucional consagrada en el artículo 241 numeral 4 se torna pertinente para el tema objeto de estudio. En efecto, tal y como fue reseñado en líneas precedentes, tres ciudadanos alegaron la presunta inconstitucionalidad del artículo 1616 del Código Civil colombiano. Para ello, ejercieron la denominada demanda de inconstitucionalidad mencionada por el artículo 241 constitucional referido. La misma corresponde a una acción pública que busca impugnar ante la Corte Constitucional, actos jurídicos considerados violatorios de la Carta Política por parte de quienes la promueven. La titularidad corresponde a todos los miembros de la sociedad sin excepción alguna, y la misma se encuentra presta a instaurarse, de forma general, en cualquier tiempo $^{(12)}$ (Henao 2013, 145).

En este sentido, la demanda de inconstitucionalidad o inexequibilidad se considera una solicitud por parte de los ciudadanos, que se promueve con el fin de extraer del sistema jurídico una norma jurídica o acto jurídico en concreto que contraría la norma fundamental. Este fue precisamente, el objetivo buscado por los ciudadanos que instauraron la respectiva demanda contra el artículo 1616 del Código Civil. Ante este espectro de cosas, la Corte Constitucional, en ejercicio de la facultad otorgada por la propia Carta Fundamental, debió pronunciarse al respecto mediante el ejercicio del control de constitucionalidad, lo cual implicó, en todo caso, interpretar el contenido del precepto y determinar su conformidad con la Carta Política. El balance de esta actuación puso de manifiesto una contradicción aparente con la Constitución Nacional, pues el artículo 1616 de derecho privado fue declarado exequible.

Vale recalcar que la Corte Constitucional colombiana en el ejercicio de este control, utilizó, entre otros aspectos, la Convención de Viena y los Principios UNIDROIT como parámetros de referencia para determinar la constitucionalidad del precepto mencionado. Esta potestad puede explicarse considerando el artículo 230 de la Carta Política, el cual establece que "los jueces, en sus providencias, sólo están sometidos al imperio de la ley. La equidad, la jurisprudencia, los principios generales del derecho y la doctrina son criterios auxiliares de la actividad judicial".

En relación a los diversos criterios auxiliares que establece el artículo en mención, se debe aclarar que su enumeración no tiene sentido taxativo. En efecto, en Sentencia C-486 de 1993, siendo Magistrado Ponente el Doctor Eduardo Cifuentes Muñoz, la Corte Constitucional analizó, entre otros aspectos, el rol que juega la costumbre como fuente de derecho en el ordenamiento jurídico colombiano, estableciendo que la misma pese a no encontrarse explícitamente determinada como una de acuerdo al artículo 230 de la Constitución Política, debía atribuírsele un valor de tal por cuanto:

"(...) Si bien el segundo inciso del artículo 230 de la CP sólo menciona como criterios auxiliares de la actividad judicial a la equidad, la jurisprudencia y los principios generales del derecho, no excluye en modo alguno otros criterios que sea indispensables en relación con la materia

(12) El artículo 242 de la Constitución Política establece que la acción de inconstitucionalidad por vicios de forma sobre las leyes caducan al término de un año luego de la publicación de dicho acto (numeral 3). El mismo término se emplea para el análisis de asuntos concernientes a la reforma de la Constitución, convocatoria a referendos, Asamblea Nacional Constituyente, consultas populares y plebiscitos. 
sujeta a su decisión y que a este respecto revistan utilidad como apoyo de la misma. La mención que la Carta hace de aquéllas, no se orienta a asignarles el papel de únicos criterios auxiliares del juez, sino a calificarlas justamente como auxiliares y, por esta vía, despojarlas de cualquier posibilidad de servir como fuentes directas y principales de las providencias judiciales". (Corte Constitucional, 1993).

Al respecto, debe considerarse que la Corte Constitucional no ha cambiado el sentido de esta decisión, pues se ha pronunciado de igual forma en otras ocasiones sentando precedente, como sucedió en el caso de la Sentencia C-083 de 1995. Igualmente, en Sentencia C-1287 de 2001, este Alto Tribunal consideró que los valores, siendo normas de textura abierta y diferentes a los principios generales del derecho, son efectivamente criterios auxiliares interpretativos del ordenamiento jurídico en su conjunto.

Gracias a estas razones, la Corte Constitucional colombiana en el ejercicio del control de constitucionalidad no se limita a los criterios auxiliares de interpretación referidos por la norma fundamental de forma explícita. Así, entre los distintos elementos de interpretación que ha utilizado la Corte de forma constante y que no están consagrados en el artículo 230 constitucional, se encuentran los instrumentos de derecho internacional, incluyendo no sólo Tratados en los cuales Colombia no es un Estado Parte y Jurisprudencia del Tribunal Europeo de Derechos Humanos, sino también la lex mercatoria y normas de soft law como es el caso de los Principios UNIDROIT. La Sentencia C-1008 de 2010 reseñada en líneas precedentes es muestra de este último caso.

En este sentido entonces, se torna evidente que la Corte Constitucional colombiana cuenta con amplia potestad para tomar en consideración cualquier tipo de elemento internacional o doctrina interna, que considere relevante para interpretar el tema que se encuentre analizando, así como también para incrementar la solidez de la línea argumentativa que desarrolla en un caso en concreto. La inclusión cada vez más constante de pronunciamientos e instrumentos internacionales en las decisiones de este Alto Tribunal, como sucedió en el caso de la Sentencia C-1008 de 2010, se debe al desarrollo del ordenamiento jurídico colombiano que ha sido impulsado por la globalización. De ahí que se considere al derecho internacional como fuente del derecho constitucional (Monroy Cabra 2008).

\section{Conclusiones}

La Convención de Viena sobre Compraventa Internacional de Mercaderías, como máxima exponente del derecho material uniforme, tiene vigencia en el sistema jurídico colombiano a través de la Ley 32 del 30 de diciembre de 1992; así pues, resulta incuestionable su consolidación como fuente mediante la cual la Corte Constitucional de Colombia puede fundamentar la exequibilidad de una norma del Código Civil, como fue el caso del artículo 1616 en la Sentencia C-1008 de 2010 sobre responsabilidad del deudor en materia de indemnización de perjuicios en el ámbito contractual privado.
Lo que podría ser más controvertido es que la Corte Constitucional realice la misma fundamentación mediante un artículo contenido en los Principios UNIDROIT sobre los Contratos Comerciales Internacionales, texto considerado una expresión de la lex mercatoria, que precisamente destaca por su carácter anacional, privado y espontáneo. Recordemos que el artículo 230 de la Constitución Política, determina que en sus providencias los jueces sólo están sometidos al imperio de la ley; enumerando seguidamente, a la equidad, la jurisprudencia, los principios generales del derecho y la doctrina como criterios auxiliares de la actividad judicial. Sin embargo, la jurisprudencia de la misma Corte, ha dictaminado que si bien el artículo 230 de la CP sólo menciona esos criterios auxiliares de la actividad judicial, no excluye en modo alguno a otros que sean indispensables en relación con la materia sujeta a su decisión y que a este respecto revistan utilidad como apoyo de la misma.

Así pues, sea la oportunidad para mencionar que, sin perjuicio de la facultad legal que tiene la Corte Constitucional para recurrir a criterios auxiliares de interpretación, lo cierto es que fundamentar la constitucionalidad de una norma del Código Civil, que data de 1887 , en normas a posteriori con una clara dimensión internacional y que, tratándose de los Principios UNIDROIT, no vinculan en estricto sentido, resulta ser poco ortodoxo y; sin duda, novedoso. Decisiones de esta índole exponen la importancia de estos instrumentos de armonización del derecho no sólo en ámbitos privados individuales, sino en contextos generales, en consideración a los efectos erga omnes de las sentencias de constitucionalidad.

En definitiva, la Corte Constitucional colombiana en el ejercicio del control de constitucionalidad, no se encuentra limitada a los criterios auxiliares de interpretación referidos por el artículo 230 de la CP de forma explícita. De tal manera, se vale igualmente de instrumentos de Derecho internacional, incluyendo no sólo Tratados en los cuales Colombia no es un Estado Parte y Jurisprudencia del Tribunal Europeo de Derechos Humanos, sino también a la lex mercatoria y el soft law como es el caso de los Principios UNIDROIT. 


\section{Referencias bibliográficas}

Bolaños, Linares. 2004. Contratación Internacional. México: Editorial Porrúa.

Cadena, Walter. 2006. Impacto en Colombia de la Lex Mercatoria. Revista Electrónica Civilizar Universidad Sergio Arboleda, 11. Recuperado el 15 de marzo de 2015 de http://www. usergioarboleda.edu.co/civilizar/revista11/Impacto\%20_Lex_ Mercatoria.pdf. https://doi.org/10.22518/16578953.755

Cándano, Mabel. 2018. "La unificación del derecho comercial internacional: nueva lex mercatoria como alternativa al derecho estatal". Revista Prolegómenos Derechos y Valores. Bogotá: Universidad Militar Nueva Granada, (pp. 149-162). https://doi. org/10.18359/prole.3001

Campuzano Díaz, Beatriz. 2000. La repercusión del Convenio de Viena de 11 de abril de 1980 en el ámbito de la compraventa de mercadería. Sevilla: Universidad de Sevilla.

CNUDMI. 2010. Compendio de jurisprudencia basada en la Convención de las Naciones Unidas sobre los Contratos de Compraventa Internacional de Mercaderías. New York: Naciones Unidas.

Corte Constitucional. 1993. Sentencia C-486 del 28 de octubre. Magistrado Ponente Eduardo Cifuentes Muñoz.

2000a. Sentencia C-529 del 10 de mayo. Magistrado Ponente Carlos Antonio Barrera Carbonell.

2000b. Sentencia C-569 del 17 de mayo. Magistrado Ponente Carlos Gaviria Díaz.

2001. Sentencia C-1287 del 05 de diciembre. Magistrado Ponente Marco Gerardo Monroy Cabra.

2008. Sentencia C-1154 del 26 de noviembre. Magistrada Ponente Clara Inés Vargas Hernández.

2010. Sentencia C-1008 del 09 de diciembre. Magistrado Ponente Luis Ernesto Vargas Silva.

2013. Sentencia C-400 del 03 de julio. Magistrado Ponente Nilson Pinilla Pinilla.

Corte Suprema de Justicia. Sala de Casación Civil. 1999. Sentencia del 19 de febrero, Expediente No. 5099, Magistrado Ponente Carlos Esteban Jaramillo Schloss.

1996. Sentencia del 14 de marzo, Expediente No. 4738, Magistrado Ponente Pedro Lafont Pianetta.

Esplugues Mota, Carlos, Palao Moreno, Guillermo y Fernández Masiá, Enrique. 2003. Derecho del Comercio Internacional. Valencia: Tirant lo Blanch.

Fernández Rozas, José Carlos. 2002. Teoría y Praxis en la codificación del Derecho de los negocios internacionales. En Cursos de Derecho Internacional y Relaciones Internacionales de Vitoria-Gasteiz, 2001. Bilbao: Universidad del País Vasco, 81-215.

Henao Hidrón, Javier. 2013. Panorama del derecho constitucional colombiano. Decimocuarta edición. Bogotá: Temis S.A.
Hernández Galindo, José Gregorio 2013. El concepto de inconstitucionalidad en el derecho contemporáneo. Bogotá: Temis S.A.

Kelsen, Hans. 1995. Teoría General del Derecho y del Estado. Quinta reimpresión de la Segunda edición. México: Universidad Nacional Autónoma de México.

Madrid Martínez, Claudia. 2013. "Notas sobre la lex mercatoria: entre el silencio del legislador europeo y el silencio de los Estados americanos. Derecho internacional privado y Derecho de la Integración". Libro Homenaje a Roberto Díaz Labrano. (Coord. J. Moreno Rodríguez y D. Fernández Arroyo). Asunción: CEDEP, 333-354.

Mesa Naranjo, Vladimiro. 2014. Teoría Constitucional e Instituciones Políticas. Duodécima edición. Bogotá: Temis S.A.

Momberg-Uribe, Rodrigo y Pino-Emhart, Alberto. 2018. "Los contratos de larga duración en la edición 2016 de los Principios Unidroit sobre contratos comerciales internacionales". Revista Chilena de Derecho Privado 30: 163-191. https://doi.org/10.4067/s071880722018000100163

Monroy Cabra, Marco Gerardo 2008. "EI Derecho Internacional como fuente del Derecho Constitucional". Anuario Colombiano de Derecho Internacional, 107-138.

Ochoa Muñoz, J. 2005. "Aplicación de la lex mercatoria". Ley de Derecho Internacional Privado Comentada. Cord. Tatiana B. de Maekelt, Ivette Esis Villarroel y Carla resende. Tomo II. Caracas: Universidad Central de Venezuela, 805-832.

Oviedo Albán, Jorge. 2002. La unificación del Derecho privado: UNIDROIT y los Principios para los Contratos comerciales Internacionales. Conferencia presentada por el autor en el seminario internacional "Compraventa internacional," realizado en la ciudad de Bogotá - Colombia entre los días 16 a 18 de mayo de 2002. Colegio Mayor de Nuestra Señora del Rosario, La Cámara de Comercio de Bogotá y la Pontificia Universidad Javeriana. Recuperado el 15 de marzo de 2015. http://www.cisg.law. pace.edu/cisg/biblio/oviedoalban3.html\#*

Pablo-Romero Gil-Delgado, María. 2014. Avances en la Aplicación de los Principios UNIDROIT sobre los Contratos Comerciales Internacionales. Cláusulas Modelo para los Contratantes. Cuadernos de Derecho 
Transnacional. Vol. 6, número 1. Madrid: Universidad Carlos III, 253-268.

Piccato Rodríguez, Antonio. 2006. Teoría del derecho. México: IURE Editores.

Quinche Ramírez, Manuel. F. 2013. El control de constitucionalidad. 2da edición. Bogotá: Editorial Ibáñez.

Ruiz Castellanos, Gerardo. 2016. "La nueva lex mercatoria". Iuris Tantum Revista Boliviana de Derecho 21. Santa Cruz: Fundación luris Tantum, 340-351.
Tafur González, Álvaro. 2010. Código Civil Anotado. Vigesimonovena edición. Bogotá: Leyer.

Tamayo Jaramillo, Javier. 1999. De la responsabilidad civil. Tomo I. Bogotá: Temis S.A.

Tolosa Villabona, Luis. 2017. "De los principios del Derecho Obligacional y Contractual contemporáneo". Revista Estudios Socio-Jurídicos, 19 (2). Bogotá Universidad del Rosario, 13-61.

Velásquez Gómez, Hernán Darío. 2010. Estudio sobre las obligaciones. Bogotá: Temis S.A.

Vivas, Barrera. Tania. 2012. "El Amparo mexicano y la Acción de Tutela colombiana. Un ejercicio de Derecho Constitucional comparado en Latinoamérica". Revista Pensamiento Jurídico 33, 14-66. 